DOI: 10.12731/2658-6649-2019-11-5-2-17-22

УДК 616.65-002-006

\title{
СОСТОЯНИЕ СИСТЕМЫ \\ ГЕМОСТАЗА У БОЛЬНЫХ АДЕНОМОЙ И РАКОМ ПРЕДСТАТЕЛЬНОЙ ЖЕЛЕЗЫ
}

Алымова Е.В., Смирнова О.В., Каспаров Э.В., Титова Н.М.

Обследовано 161 мужчина в возрасте от 45 до 83 лет с различной стадией заболевания. Среди обследованных выделены три группь: больных аденомой простаты - 46 пациентов, группа больных раком предстательной железы - 53 пациента, группа сравнения - 48 относительно здоровых мужчин той же возрастной категории. Всем обследованным проводилось биохимическое исследование крови с определением компонентов системь гемостаза, характеризующих все звенья свертывающей системы крови: АЧТВ, ПТВ, МНО, фибриноген. Цель исследования - выявить особенности системы гемостаза у больных аденомой и раком простаты.

Ключевые слова: аденома простаты;; рак предстательной железы; свертываемость крови; гемостаз.

\section{CONDITION OF THE HEMOSTASIS SYSTEM IN PATIENTS WITH ADENOMA AND PROSTATE CANCER CANCER}

\author{
Alymova E.V., Smirnova O.V., Kasparov E.V., Titova N.M.
}

161 men aged 45 to 83 years old with a different stage of the disease were examined. Among the surveyed, three groups were distinguished: patients with prostate adenoma - 46 patients, a group of patients with prostate cancer - 53 patients, the comparison group - 48 relatively healthy men of the same age category. All patients underwent biochemical blood tests with the definition of hemostasis system components that characterize all parts of the blood coagulation system: APTT, PT, PI, INR, blood fibrinogen level, thrombin time. The purpose of the study is to identify the features of the hemostatic system in patients with adenoma and prostate cancer.

Keywords: adenoma prostate; cancer prostate; hemostasis system; blood clotting. 


\section{Введение}

Доброкачественная гиперплазия предстательной железы (ДГПЖ) одно из наиболее распространенных заболеваний урологии. Хроническое воспаление запускает следующие циклические реакции: клетки предстательной железы растут за счет стимуляции воспалительными клетками, продуцирующих цитокины; цитокины секретируются клетками простаты;в свою очередь, увеличение объема простаты запускает рост простатических клеток [4]. Рак предстательной железы (РПЖ) занимает второе место по смертности среди пожилых мужчин и является одним из наиболее часто диагностируемых заболеваний. Высокий уровень смертности от данного заболевания, вероятнее всего, обусловлен местно распространенной или метастатической формой злокачественного новообразования [5].

Изучение факторов, определяющих риск развития РПЖ, является актуальным направлением в своевременной диагностике данного заболевания. Так, установлены определенные факторы риска развития злокачественного новообразования предстательной железы: наследственность,возраст, национальность [6]. Отягощенная наследственность свидетельствует о том, что у таких больных заболевание развивается, на 6-7 лет раньше, чем в спорадических случаях [7]. Система гемостаза реагирует одной из первых на развитие опухоли, что обусловленоувеличением риска тромботических осложнений.

В свою очередь, это может объясняться пожилым возрастом, иммобилизацией в виду тяжелого общего состояния, компрессией новообразования на венозные сплетения с замедлением кровотока, протромботического влияния пролифирирующих клеток [1]. Аденома -доброкачественное новообразование, которое может перерождаться в злокачественную форму [3]. Большинство исследователей полагает, что метастатический РПЖ ассоциирован с развитием гиперфибринолитического состояния,посредством избыточного выделения в кровоток активаторов плазминогена [2]. Исходя из этого, целью исследования явилось: изучить состояние гемостаза при аденоме и раке предстательной железы.

\section{Материалы и методы}

Объектом исследования служила сыворотка больных аденомой простаты (46 человек) и больных раком предстательной железы (53 человека), в качестве контрольной группы было отобрано 48 практически здоровых мужчин, средний возраст каждой из групп составил 65 лет. Скрининго- 
вые показатели: АЧТВ, ПТВ, МНО, фибриноген. Статистическая обработка результатов произведена с использованием программного обеспечения STATISTICA10.0 и MicrosoftExcel. Полученные данные представлены в виде медианы $(\mathrm{Me}), 25$ и 75 процентилей $\left(\mathrm{P}_{25}\right.$ и $\left.\mathrm{P}_{75}\right)$, для сравнения показателей между группами применялся U-критерий Манна-Уитни.

\section{Результаты}

В ходе проведенного нами исследования были получены результаты основных показателей системы гемостаза у больных, аденомой и раком предстательной железы. Для оценки образования протромбиназы в первой фазе плазменного гемостаза используетсяАЧТВ. Это тест показывает общие представления о системе свертывания крови. АЧТВ - тест, который подходит для выявления исключительно плазменных дефектов внутренней системы активации X фактора в первой фазе свертывания крови (образование протромбиназы).

Удлинение АЧТВ у больных раком простаты указывает на преобладание гипокоагуляции. Протромбиновое время (ПТВ) характеризует первую и вторую (про/ - тромбинообразование соответственно) фазы плазменного гемостаза и освещает активность протромбинового комплекса (факторов VII, V, X и собственно протромбина - фактора II). У больных обеих исследуемых групп отмечено увеличение ПТВ, что говорит о наклонности к гипокоагуляции и может зависеть от различных причин: недостаточность одного или нескольких факторов протромбинового комплекса, синтезируемых печенью, амилоидоз. При возникновении острых воспалительных заболеваний и отмирания тканей содержание фибриногена в крови повышается, так же фибриноген влияет на скорость оседания эритроцитов (СОЭ). Работу системы гемостаза характеризуетмеждународное нормализованное отношение (МНО) показатель, который получают расчетным путем при анализе следующих данных: время, за которое сворачивается кровь, чувствительность тромбопластина и средний уровень протромбина. При исследуемой патологии МНО находится в пределах клинической нормы.

\section{Заключение}

Исходя из проведенного исследования, можно отметить незначительную гипокоагуляцию, как при ДГПЖ, так и при РП. Достоверное увеличение белка острой фазы - фибриногена, что указывает на усиление воспалительного процесса, при аденоме, и раке предстательной железы. 


\section{Список литературы}

1. Женило В.М., Константинова Г.А., Малыгин В.Н. Состояние системы гемостаза при злокачественных новообразованиях предстательной железы и мочевого пузыря // Новые технологии, 2012.

2. Шиффман Ф.Дж. Патофизиология крови. Пер. с англ. М.-СПб.: «Издательство БИНОМ»-«Невский Диалект», 2000. 448 с.

3. http://opuholi.org/dobrokachestvennaya-opuxol/adenoma/rak-adenomapredstatelnoj-zhelezy-simptomy-i-lechenie.html

4. Григори Р. Терапия доброкачественной гиперплазии предстательной железы: в фокусе - воспаление// Русский медицинский журнал. №27. М., 2017. С. 2003-2010.

5. Солодкий В.А. Местнораспространенный и локализованный рак предстательной железы группы высокого риска прогрессирования: стратегия лечения, обзор клинических исследований// Русский медицинский журнал. №27 М., 2017. C. 2015-2018.

6. Gronberg H., Damber L., Damber J.E. Familial prostate cancer in Sweden. A nationwide register cohort study. Cancer 1996 Jan; 77(1):138-43.

7. Bratt O. Hereditary prostate cancer: clinical aspects. J Urol 2002 Sep;168(3): 906-13.

8. Влияние общих пресных ванн и физических тренировок при разной длительности назначения на физическую работоспособность больных стабильной стенокардией с нарушением ритма. Клеменков А.С., Фурсова Я.Е., Клеменков С.В., Каспаров Э.В. и др. Фундаментальные исследования. 2006. № 3. C. 13.

\section{References}

1. Zhenilo V.M., Konstantinova G.A., Malygin V.N. Sostoyanie sistemy gemostaza pri zlokachestvennykh novoobrazovaniyakh predstatel'nojzhelezy I mochevogo puzyrya [The state of the hemostatic system in malignant neoplasms of the prostate gland and bladder]. Novyetekhnologii, 2012.

2. Shiffman F.Dzh. Patofiziologiyakrovi [Blood pathophysiology]. M.-SPb.: «Izdatel'stvo BINOM»-«NevskijDialekt», 2000. 448 p.

3. http://opuholi.org/dobrokachestvennaya-opuxol/adenoma/rak-adenoma-predstatelnoj-zhelezy-simptomy-i-lechenie.html

4. Grigori R. Russkij meditsinskij zhurnal. №27. M., 2017, pp. 2003-2010.

5. Solodkij V.A. Mestnorasprostranennyj I lokalizovannyj rak predstatel'noj zhelezy gruppy vysokogo riska progressirovaniya: strategiyalecheniya, obzor klinicheskikh issledovanij [Locally advanced and localized prostate cancer at 
high risk of progression: treatment strategy, review of clinical studies]. Russkij meditsinskij zhurnal. №27. M., 2017, pp. 2015-2018.

6. Gronberg H., Damber L., Damber J.E. Familial prostate cancer in Sweden. A nationwide register cohort study. Cancer 1996 Jan;77(1):138-43.

7. Bratt O. Hereditary prostate cancer: clinical aspects. JUrol 2002 Sep;168(3): 906-13.

8. Klemenkov A.S., Fursova Ya.E., Klemenkov S.V., Kasparov E.V. et al. Vliyanie obshchih presnyh vann i fizicheskih trenirovok pri raznoj dlitel'nosti naznacheniya na fizicheskuyu rabotosposobnost' bol'nyh stabil'noj stenokardiej s narusheniem ritma [The effect of common freshwater baths and physical training for different duration of the appointment on the physical performance of patients with stable angina with rhythm disturbances]. Fundamental'nye issledovaniya [Fundamental research]. 2006. № 3. P. 13.

\section{ДАННЫЕ ОБ АВТОРАХ}

Алымова Екатерина Викторовна, аспирант

Научно-исследовательский институт медицинских проблем народов Севера Федеральный исследовательский центр «Красноярский научный иентр Сибирского отделения Российской академии наук»

ул. Партизана Железняка, ЗГ, г. Красноярск, 660022, Российская Федерация

katial@bk.ru

Смирнова Ольга Валентиновна, заведующая лабораторий патофизиологии д.м.н., профессор

Научно-исследовательский институт медицинских проблем народов Севера Федеральный исследовательский центр «Красноярский научный иентр Сибирского отделения Российской академии наук» ул. Партизана Железняка, ЗГ, г. Красноярск, 660022, Российская Федераиия ovsmirnova71@mail.ru

Каспаров Эдуард Вильямович, директор, Д.м.н., профессор

Научно-исследовательский институт медииинских проблем народов Севера Федеральныий исследовательский центр «Красноярский научный иентр Сибирского отделения Российской академии наук» ул. Партизана Железняка, ЗГ, г. Красноярск, 660022, Российская Федерачия 
Титова Надежда Митрофановна, преподаватель, к.б.н., доцент кафедра медицинской биологии Институт фундаментальной биологии и биотехнологии

Сибирский Федеральный Университет

nр. Свободный, 79, г. Красноярск, 660041, Российская Федерачия

\section{DATA ABOUT THE AUTHORS}

Alymova Ekaterina Victorovna, Graduate student

Research Institute of medical problems of the North, Federal research center of the Krasnoyarsk scientific center of the Siberian branch of the Russian Academy of Sciences

3G, Partizan Zheleznyak Str., Krasnoyarsk, 660022, Russian Federation katial@bk.ru

Smirnova Olga Valentinovna, Head of the Laboratory of Pathophysiology, MD, Professor

Research Institute of medical problems of the North, Federal research center of the Krasnoyarsk scientific center of the Siberian branch of the Russian Academy of Sciences

3G, Partizan Zheleznyak Str., Krasnoyarsk, 660022, Russian Federation ovsmirnova71@mail.ru

Kasparov Eduard Vil'yamovich, director, MD, Professor

Research Institute of medical problems of the North, Federal research center of the Krasnoyarsk scientific center of the Siberian branch of the Russian Academy of Sciences

3G, Partizan Zheleznyak Str., Krasnoyarsk, 660022, Russian Federation

Titova Nadezhda Mitrofanovna, teacher, Ph.D., assistant professor, Department of Medical Biology, Institute of Fundamental Biology and Biotechnology

Siberian Federal University

79, Prospect Svobodny, Krasnoyarsk, 660041, Russian Federation 